\title{
PRODUCT PERSONALIZATION: STIMULATING ATTACHMENT BETWEEN PRODUCT AND CONSUMERS
}

\author{
G. NILUSHI SITHARA FERNANDO ${ }^{1} \&$ W. M. N. DILSHANI RANASINGHE ${ }^{2}$ \\ 1, 2University of Moratuwa, Sri Lanka \\ 1nishisithara11@gmail.com,2dilshanir@uom.lk
}

\begin{abstract}
This study investigates about how product personalization can be used to stimulate attachment between products and Sri Lankan consumers. Through the literature it was evident that, consumer involvement and the final personalized product, in product personalization can act as the main sources which evoke positive emotions, through self-expression, enjoyment and memories, to stimulate attachment. Three hypothetical scenarios of product personalization followed by online questionnaires about the experience were created to verify these findings of literature. The feeling of attachment was evident towards these personalized products as discovered through literature, especially in the responses of female participants. It was also evident that they would most likely to protect and use the product for a longer time than male participants. Several methods providing personalization options to stimulate long term attachment were identified together with the literature and primary data. Additionally, providing adequate options to personalize the product to their satisfaction, requirement of less technical knowledge in personalization process and already having a need of personalizing the primary functionality of the product were identified to be promoting the feeling of attachment.
\end{abstract}

Keywords: Product personalization, Attachment, Emotional bond

\section{Introduction}

Rapidly developing technology has created a new "throwaway culture" (Page, 2014). Perfectly functioning products are quickly becoming obsolete (Fels et al., 2017). Consumers lose the interest on the available product soon as a new model develops. This is evident in most technology-based products such as laptops, smartphones, vehicles etc. While thrown away products cause pollution, replacement of scarce resources which are used up during production in forms of material and energy, effects the environment. This will create a huge impact on the already polluted environment. But according to the studies of Mugge (2007), when a consumer experience a strong attachment with a product, they are more likely to care, repair and postpone its replacement, increasing its ownership time.

Studies of Mugge et. al (2009) identified product personalization as a potential design strategy which could be used stimulates attachment with the product. Therefore, knowledge on how product personalization stimulates attachment can be used to design products which have longer life time, supporting for an environmentally friendly future.

\section{Identification on the Relationship between Attachment and Product Personalization}

A literature study was carried out in order to identify what attachment is and how consumers gets attached towards products, to form a theoretical base on about how attachment is stimulated by product personalization.

\subsection{PRODUCT ATTACHMENT}

Related to interpersonal relationships, based on the studies of the British psychologist John Bowlby, attachment is defined as an emotional-laden target-specific bond between two persons (Mugge et al. 2010). Similarly, product attachment has been defined as the emotional bond and feelings that connect a consumer with a product (Park and Yoo, 2018).

According to Ko et al. (2015), attachment occurs when there is a strong commitment and emotions towards a product. These consumers tend to invest a great deal of psychic and emotional energy on these products (Schultz et al, 1989). They cherish this relationship and would exhibit more protective 
behaviour (Mugge, 2007), would repair them if they are damaged and would gain some enjoyment from doing this as well (Page, 2014). According to Mugge et al. (2008) consumers identify these products as extraordinary and favourites. They are considered as irreplaceable, indispensable products and these consumers will try to keep hanging on to them increasing the product lifetime (Schifferstein and Zwartkruis-Pelgrim 2008). Therefore, product attachment can be defined as an emotional connection that consumer feels with a product, which increases the personal value of it.

\subsection{DETERMINANTS OF ATTACHMENT}

Several studies were conducted by scholars to identify about the determinants which cause attachment. Mugge (2007) identified self-expression (expresses the unique identity of the consumer), group affiliation (expresses the consumer's belongingness to a group), memories (reminds of the past) and pleasure as determinants of product attachment to ordinary durables. Schifferstein and Zawarkruis-Pelgrim (2008) identified seven possible determinants of attachment: self-identity, enjoyment, memories to persons, places, and events, life vision, utility, reliability, market value and out of them, they identified that memories and enjoyment as positively contributing to the degree of attachment. Memories, pleasure, usability, reliability and the trust in the product were identified as causes of attachment by Page (2014). Out of them memories and pleasure were identified as primary causes. Self-expression can be categorized as expressing private self and expressing public self (Mugge et al, 2006, Schultz, 1989). Therefore group affiliation (expressing public self) can be included to the category of self- expression. Based on these studies, self-expression, enjoyment and memories can be identified as prominent determinants of attachment.

\subsection{STIMULATION OF ATTACHMENT THROUGH PRODUCT PERSONALIZATION}

As defined by Blom (2000), "product personalization is defined as a process that defines or changes the appearance or functionality of a product to increase its personal relevance to an individual" (Mugge et. al 2009, p. 468). Personalized products meet specific needs and express the unique tastes and preferences of the consumer (Kudus, 2017). Therefore these products can function and look exact the way which consumer wants.

For a product to be personalized to meet the exact individual requirements of the consumer, some involvement of the consumer is required. The designer should offer more decision-making power to the consumer, to operate as co-designers. Therefore, in addition to the designing of the product, the designer should design the process of personalization.

\subsubsection{Relationship between Attachment and Emotions}

Attachment between a consumer and product implies the existence of an emotional tie between the consumer and the product. (Schifferstein and Zwartkruis-Pelgrim, 2008) But, association of emotions doesn't always suggest the presence of product attachment. On interpersonal relationships it was explained that individuals are securely attached when they are experiencing positive emotions (Simpson et al, 2007). Similarly, Mugge et al. (2008) explains that despite of huge variety of emotions, people often experience attachment to products, when positive emotions are involved.

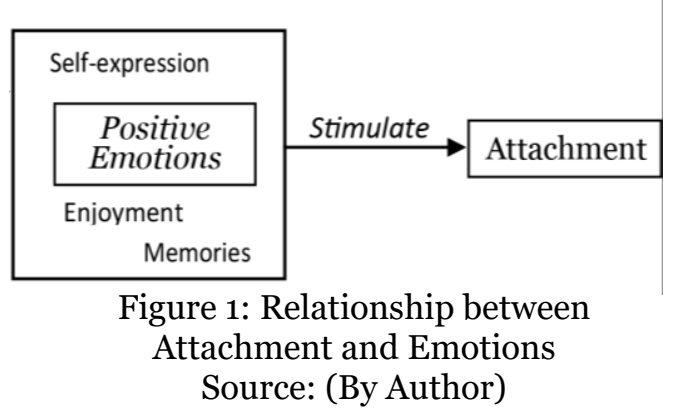


As explained previously attachment was also found to be caused by the determinants; self- expression, enjoyment and memories. These determinants have the ability to evoke positive emotions (Mugge et al., 2008). Therefore as shown in figure 1 positive emotions caused by determinants of attachment are responsible in stimulating attachment between the consumer and the product.

\subsubsection{Relationship between Product Personalization and Emotions}

Emotions are always a response to a stimulus which has a personal relevance (Destmet, 2012). There is a cause for each emotion (Desmet, 2018). For example, happiness can be evoked by a product which performs better than expected. Related to human- product interactions, Desmet (2012) identified six basic sources of positive emotions; Emotions could be evoked in,

- Response to the material qualities of the object (ex: fascination provided by a well-designed product).

- Meaning of the object.

- Interaction with the object (ex: admiration provided when opening a wine bottle smoothly and effortlessly).

- Activity that is facilitated by this interaction (ex: sense of relaxation and freedom provided when riding a motorcycle through the fields, with wind and sun).

- By the self (ex: confidence felt when wearing comfortable shoes).

- Others involved in the interaction (ex: feeling of love when receiving a gift from a special person).

Therefore in product personalization, the consumer involvement as well as the final personalized product can act as main sources which stimulate emotions as in the figure 2.

\begin{tabular}{|c|c|c|}
\hline $\begin{array}{l}\text { Consumer involvement } \\
\text { (Interaction, activity facilitated by the } \\
\text { object, self) }\end{array}$ & Stimulate & $\begin{array}{l}\text { Positive } \\
\text { Emotions }\end{array}$ \\
\hline $\begin{array}{l}\text { Personalized product } \\
\text { (Object, meaning of the object, self) }\end{array}$ & Stimulate & $\begin{array}{l}\text { Positive } \\
\text { Emotions }\end{array}$ \\
\hline
\end{tabular}

Figure 2: Relationship between Product Personalization and Emotions Source: (By Author)

\subsubsection{Relationship between Product Personalization and Attachment}

Several scholars have identified product personalization as a potential method of forming attachment (Mugge, 2007; Mugge et al, 2008; Page 2014). As discovered through the literature in the previous sections, in product personalization, consumer involvement and the final personalized product can act as the main sources which evoke positive emotions, through self-expression, enjoyment and memories, to stimulate attachment (Figure 3)

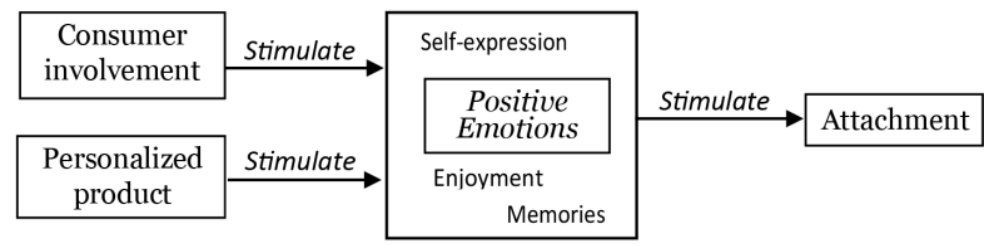

Figure 3: Conceptual model on relationship between

Product Personalization and Attachment

Source: (By Author) 


\section{Research methodology}

The study was conducted by initially allowing the respondents to participate in hypothetical scenarios to personalize the 3 types (as explained in section 3.2) of products according to the way they like, using a given set of options, in different stages of the product's lifetime.

Three products were selected as stimuli, to generalize the responses regardless of the product type. Based on this experience of product personalization both quantitative and qualitative data were collected, to identify how attachment is stimulated through product personalization, for Sri Lankan consumers. For this, a questionnaire was prepared with both close ended and open ended questions to confirm findings of literature and to gather new data.

\subsection{SAMPLE SELECTION}

For this study, male and female participants of age group 21-25 were chosen based on following reasons; This is a stage of life where individuals starts becoming free from parental familial school restrains they felt during childhood (Center on media and child health, n.d). Currently, involving the consumer in the personalization process is not a common practice for most products in Sri Lanka. At the selected age, individuals start to question the experiences, beliefs from childhood and become more willing to compromise and restructure them (State adolescent health resource center, n.d.). Therefore it is easier to adapt to new practices. Within this age group, for the current study the category, Sri Lankan students of government universities were selected because they have a large representation and exposure to individuals from different cultures, races, different socio-economic backgrounds around Sri Lanka.

\subsection{PRODUCT SELECTION}

Three tangible, functional, commonly used product categories which are commonly bought for personal usage of the general population of the selected sample were selected as stimuli for the study.

a) Umbrella- a product which doesn't usually need changes in its primary functionality (weather protection) while using.

b) Backpack- a product which usually needs its primary functionality (store and transport) to be change while using, depending on what is stored and transported.

c) Smartphone- a product which usually needs its primary functionality (communication and entertainment) to be changed based on upgrades of the technology

\section{Research Findings and Discussions}

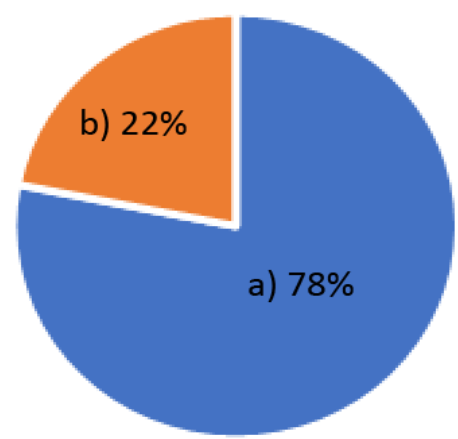

Figure 4: Preference in buying (a) personalized vs (b) ready-made product. Source: (By Author) 
A total of 128 participants ( 63 male and 65 female) completed the questionnaires related to umbrella, backpack and smartphone. 41 completed the questionnaire related umbrella (22 male and 19 female), 45 completed the questionnaire related to the backpack (20 male and 25 female) while 42 completed the questionnaire related to the smartphone ( 21 male and 21 female). Out of all these respondents, $78 \%$ preferred to buy a personalized product rather than ready-made product (Figure 4 ). Therefore, it could be concluded that majority Sri Lankan consumers prefer personalized products over ready made products.

\subsection{FEELING OF ATTACHMENT}

Respondents were given with the option of selecting "yes", "no" or "maybe" to identify whether they would feel a sense of attachment to the product which they personalized. Option "maybe" was given to filter out the responses of doubt.

$60.9 \%$ of all the respondents identified that they would definitely feel a sense of attachment to personalized products (50.7\% of male, $70.7 \%$ of female respondents). $3.1 \%$ of all respondents identified that they wouldn't feel a sense of attachment towards the product. As commented by some participants less usage of the type of product given in real life and dis-likeness for the available products in the category and feeling of highly negative emotions such as frustration by personalizing their own product are possible reasons for this. 33.6\% of participants were unable to determine whether the product would create a sense of attachment or not. Use of a hypothetical scenario of personalization about a product/process they have not yet experienced is a possible reason for this result

Based on these data it could be concluded that product personalization can have an effect on the feeling of attachment, as discovered through literature. Furthermore, it appears to be more prominent among female participants than male participants.

\subsection{REASONS FOR THE FEELING OF ATTACHMENT}

Out of all the respondents who felt a sense of attachment after participating in the hypothetical scenario of personalizing the products, $65 \%$ felt that the final product express about their-selves and $58 \%$ enjoyed participation. $96 \%$ felt either one of them.

As it was evident from the qualitative data of the questionnaire survey, the participants identified several factors as the reasons of the feeling of attachment towards the personalized products;

- The final product express, represent the consumers' identity and self- interests.

- Personal achievement accomplished by the consumers' own ideas and will.

- Unique product which is specially made to match the requirements of the user.

- Unique experience.

When considering about the number of participants who identified that they would feel attachment towards each product; 64\% identified that they would feel attachment towards backpack, 61\% towards umbrella and $57 \%$ towards smartphone. When considering the results of umbrella, it was the personalization processes enjoyed by least number of respondents, out of these 3 products. But majority felt it would express their-selves (72\%) than other two products. Enjoyment being least experienced in the personalization of umbrella could be a reason for it not being the product which stimulated attachment to most number of participants (compared to backpack). Therefore, even though self-expression is more recognized by consumers as a reason which stimulates attachment, it could be observed that enjoyment is important as well in product personalization. as explained by the literature. 
Through the qualitative data, it was observed that many identified that they already have a greater need of personalizing the functionality of the backpack while using the product; Such as changing the pocket sizes of the bag according to the situation, changing strap lengths according to the weight of the bag. As shown in Table 1 this could be a reason why majority felt attachment towards backpack, than other products.

Table 1- Identification on Presence of Determinants of Attachment

\begin{tabular}{|l|l|l|l|}
\cline { 2 - 4 } \multicolumn{1}{c|}{} & $\begin{array}{l}\text { Umbrella } \\
\text { (\%) }\end{array}$ & $\begin{array}{l}\text { Backpack } \\
\text { (\%) }\end{array}$ & $\begin{array}{l}\text { Smartphone } \\
(\%)\end{array}$ \\
\hline (i) Self expression & 72 & 69 & 54 \\
(ii) Enjoyment & 52 & 62 & 58 \\
(iii) Doesn't feel any of above & 8 & 0 & 17 \\
\hline Feeling of attachment & 61 & 64 & 57 \\
\hline
\end{tabular}

Source: (By Author)

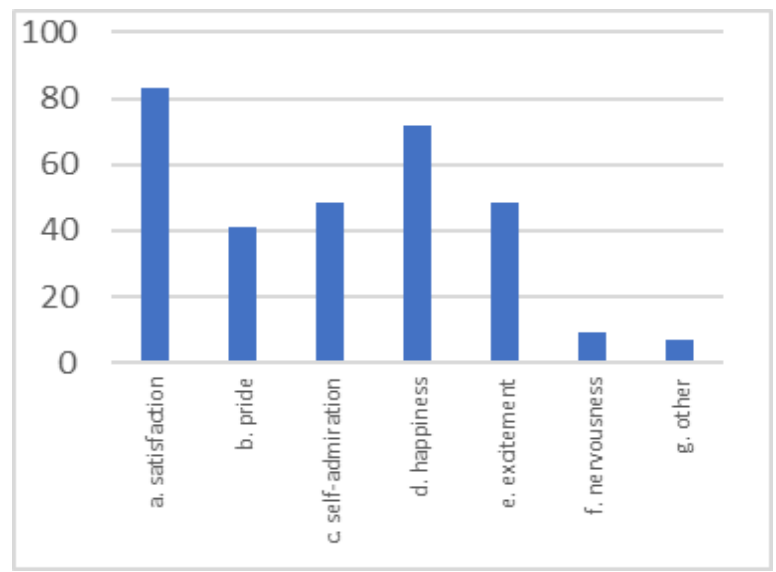

Figure 5: Emotions felt from involving in the personalization process.

Source: (By Author)

\subsection{EMOTIONS FELT BY PRODUCT PERSONALIZATION}

From the literature, it was evident that, attachment was felt as a result of stimulation of positive emotions. Confirming this, positive emotions; satisfaction (83\%), happiness (71\%), excitement (49\%), self-admiration (49\%), pride (41\%), freedom, comfort, confidence and fun were identified as emotions felt from involving in the personalization process by the participants felt a sense of attachment (Figure 5). The negative emotion frustration was evident in some of the responses of respondents who identified that they won't feel a sense of attachment

Additionally, based on the current study even though the nervousness can be considered as a negative emotion (felt by $9 \%$ of participants who felt attachment), it could be concluded that negative emotions doesn't necessarily stimulate detachment, due to the dominance of other positive emotions. 


\subsection{RESULTS OF ATTACHMENT IN PRODUCT PERSONALIZATION}

Through the literature study about products which users felt attachment, it was evident that attachment could increase the product's lifetime. But in the current study, $44 \%$ of the participants responded that they would protect it and $32 \%$ identified that they would repair and try hanging on to it if gets broken and only $19 \%$ identified that it is irreplaceable. Therefore it could be concluded that the attachment felt is short term. Confidence they developed; that they can built a similar product on their own again is a possible reason for this.

\section{Implications}

When the consumer actively participates in the process of personalization, consumers perceive the product as better fit to their preferences. During the process of personalization, if the process provides adequate options to personalize the product in the way consumer needs, it has the ability to evoke positive emotions such as satisfaction and happiness, which were observed to be the emotions most commonly felt by those who felt attachment in the case studies.

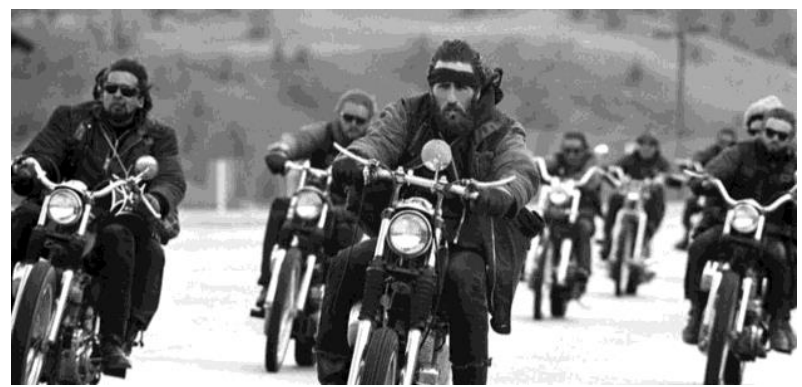

Figure 6: Hells Angels biker gang-

Public self-expression

Source: (https://www.rideapart.com/ $\operatorname{articles} / 253619 /)$

As these products are created by the consumers to fit their preferences, they express about themselves (private self), about their unique identity. Hence, they evoke emotions such as confidence, pride, and admiration related to the self. If this personalization process is executed in the presence of a group or if the final product symbolizes belongingness to a group, these products define and maintain the public self of the consumer. Therefore they can stimulate attachment via group affiliation. Harley Davidson motorcycle is an example for a product which stimulates attachment through product personalization, to some of its users through public self-expression (Figure 6). Emotions evoked due to self-expression in the personalized product last as long as the product, unless the consumers' personal preferences of self-expression changes.

As it was evident from literature, products can arouse enjoyment by satisfying senses simultaneously through superior appearance, superior functionality and through familiarity and surprise (Schifferstein and Zawarkruis-Pelgrim, 2008). Products need to provide something special and more than the expected primary functions to stimulate attachment through pleasure(Mugge et al, 2008). From the primary data, participants identified unique experience gained by personalizing their own product as a reason for the feeling of attachment. This experience can be more enhanced by designing it so that it satisfies all senses harmoniously, providing familiar and surprising activities. Here, attachment could also be stimulated by providing an appearance of ease (by providing a process which could easily be understood by the knowledge of the consumer), comfort and safety at the process of personalization. After the final product is created, the emotions can be evoked by the object because it is made according to the preferences of the consumer such as; favourite colours and shapes. 
Enjoyment through a surprising final outcome could be stimulated by providing personalization option to change the product while using product.

After involving in the process, the respondents who mostly sensed the presence of attachment were observed to be female (70.7\%) against the males (50.7\%). Also, considerable difference was observed among the female and male participants in feeling of happiness (Female-85\%, Male- 53\%) and feeling of enjoyment (Female-65\%, Male- 46\%). Biological differences as well as cultural, social and educational factors between men and women can trigger different behaviours and sensory perceptions. According to the studies of Walcher et al (2016), male brains have intensified one-sided processes while females utilize both sides of the brain in thinking. Purchasing processes of men are identified as straight forward and linear. They mostly consider about the utilitarian value. Whereas women's purchasing process is more complex and they are trying to find the perfect solution. They tend to consider about expressive or symbolic value (Walcher et al, 2016). When a ready-made product is bought, they are often not the perfect solutions which women seek. But by providing personalization facility, they can create the product according to the exact way they want. This could be a main reason for the difference between the results, in feeling of attachment, of female and male participants. More research is required on identifying how to increase the feeling happiness, enjoyment for male consumers, to stimulate the feeling of attachment through product personalization.

As it can be seen from the figure 7 , it can be observed that more female participants felt that the personalized product is irreplaceable (26\%), than it is felt by the male participants (9\%). Due to this it can be observed that many of female participants identified that they would protect it and would try to keep hanging on to it by repairing it (50\%, 36\%), than the male participants $(34 \%, 25 \%)$.

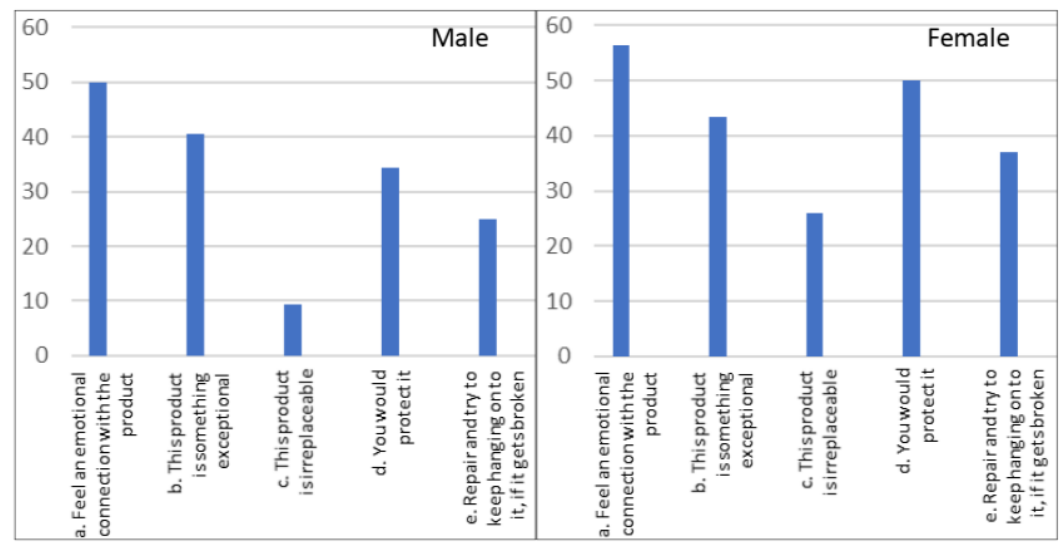

Figure 7: Variations in Results of Feeling of Attachment towards Personalized Products, Based on the Gender Source: (By Author)

But when considering the overall number of participants, in the current study, the product was not irreplaceable for a majority and attachment felt was short term. Confidence they developed; that they can built a similar product on their own again was identified as a possible reason through this study. But, there are few possible ways to make a personalized product irreplaceable.

A product will get irreplaceable if special memories get associated with it. Then, even if the product gets broken, even they have the ability to remake a similar product, many would try to repair and would try to keep hanging on to the product with special memories, lengthening its lifetime. Memories are subjective of the users' experience with the product. Even though it is somewhat beyond the control of the designer, products can be made to retain important memories by designing them to 'age 
with dignity', to retain marks of usage or by integrating specific odours during the personalization process or the final product so that they acts as trigger points to retain and remind certain memories (Mugge et al, 2008, Mugge, 2007). It is also possible to stimulate long term attachment by making each process of personalization more memorable and unique. Association of special people in the process of personalization also could create special memories.

Studies of Mugge et al (2009) identified mental/physical effort as a factor which promotes attachment. Therefore by designing the personalization process that requires mental/physical effort, which constantly remind the user of his/her personal achievement can stimulate long term attachment as well. But this personalization process should have a balance between complexity (evoke accomplishment, pride) and should be within the knowledge of the consumer (avoid negative emotions such as frustration).

\section{Conclusions}

Findings of the research explore how product personalization can stimulate attachment to the products used by Sri Lankan consumers. Happiness felt due to ease of understanding the process, satisfaction evoked by the idea of making a product suited to the users' preference, confidence and personal accomplishment felt due to being able to personalize the product on their own, fascination felt about the personalized product were some of the emotions identified. These emotions were identified to be evoked as a result of the determinants self-expression, enjoyment and memories. Through these empirical data, it was evident that consumer involvement in the personalization process as well as the final personalized product has the ability to stimulate positive emotions which stimulates attachment for Sri Lankan consumers, as conceptualized based on the literature. But significant differences were identified, in related to this feeling of attachment through product personalization, between the female and male participants.

Based on these data, implications on how these determinants could be optimized to enhance the feeling of attachment with associated with product personalization were identified. Further investigation on how to design the personalization process which stimulates long term attachment, especially for male consumers would be beneficial to design products which would aid in a sustainable future.

\section{Acknowledgement}

The success of this research required a lot of assistance and guidance from many, who I owe a great thanks to. My sincere gratitude goes to my research supervisor, Senior lecturer Mrs. Dilshani Ranasinghe, Department of Integrated design, for the guidance and immense support provided, senior lecturer Mrs. Melanie Dissanayake, Dr. Sumanthri Samarawickrama and Dr. Pradeep Peiris for providing all the necessary information and guidance in developing a successful research. My special thanks goes to all the participants of the research, for the assistance provided by spending their valuable time.

\section{References}

Blom, Jan O. (2000), Personalization - a Taxonomy, in Chi 2000 Conference on Human Factors and Computing Systems, New York, 313-314.

Center on media and child health (n.d). Young Adults: Ages 20-25. Retrieved June 15, 2019, from

http://cmch.tv/parents/young-adults-ages-20-25/

Desmet, P. M. A. (2012). Faces of product pleasure: 25 positive emotions in human-product interactions. International Journal of Design, 6(2), 1-29.

Desmet, P.M.A. (2018). 700+ Product Emotions. Delft University of Technology, The Netherlands. ISBN/EAN: 978-94-6186921-0

Fels, A., Falk B., Schmitt R. (2017). User-driven customization and customer loyalty: A survey. Procedia CIRP 60, 410-415. doi: 10.1016/j.procir.2017.02.013 
Ko K., Ramirez M. and Ward S. (2015). A framework for understanding the role of product attachment in enabling sustainable consumption of sustainable household furniture. Product lifetimes and the environment. 175-183. Retrieved from https://www.plateconference.org

Kudus, S. I. A. (2017). The Value Of Personalised Consumer Product Design Facilitated Through Additive Manufacturing Technology. DOI: 10.13140/RG.2.2.36578.58563.

Mugge, R., Schiffertein R., and Schoormans, J. P. L.(2006) Product Attachment and Product Lifetime: The Role of Personality Congruity and Fashion. European Advances in Consumer Research, 7, 460-466.

Mugge, R. (2007) Product Attachment, PhD, Delft University of Technology, Netherlands

Mugge,R., Schiffertein H.N.J and Schoormans Jan P.L. (2008). Product Attachment: Design Strategies to Stimulate Emotional Bonding to Products, 425-440. Retrieved from https://www.academia.edu/ 14973255/Product_attachment_Design_strategies_to_stimulate_the_emotional_bonding_to_products

Mugge,R., Schiffertein H.N.J and Schoormans Jan P.L. (2009). Emotional bonding with personalized products. Journal of Engineering Design, 2O, 467-476. DOI: 10.1080/0954482080269855

Mugge,R., Schiffertein H.N.J and Schoormans Jan P.L. (2010). Product attachment and satisfaction: Understanding consumers' post purchase behaviour. Journal of Consumer marketing, 22(3), 271-282, DOI: 10.1108/07363761011038347 Page, T., (2014) 'Product Attachment and replacement: implications for sustainable design', Int. J. Sustainable Design, 2(3), 265-282

Park, M. and Yoo J. (2018). Benefits of mass customized products: moderating role of product involvement and fashion innovativeness. Heliyon, 4, DOI: 10.1016/j.heliyon.2018.eo053

Schiffertein, H. N. J., \& Zwartkruis-Pelgrim, E. P. H. (2008). Consumer-product attachment: Measurement and design implications. International Journal of Design. 2(3), 1-13.

Schultz, Susan E., Robert E. Kleine, and Jerome B. Kernan (1989), “'These Are a Few of My Favorite Things.' toward an Explication of Attachment as a Consumer Behavior Construct," in Advances in Consumer Research, Vol. 16, Ed. Thomas Scrull, Provo: UT: Association for Consumer Research, 359-366.

Simpson, J. A, Collins W. A., Tran S. \& Haydon K. C. (2007). Attachment and the Experience and Expression of Emotions in Romantic Relationships: A Developmental Perspective. Journal of Personality and Social Psychology, 92(2), 355-367, DOI: 10.1037/0022-3514.92.2.355

State adolescent health resource center (n.d.). Developmental Tasks and Attributes of- Late Adolescence/Young Adulthood.Retrieved June 15, 2019, fromhttp://www.amchp.org/programsandtopics/

AdolescentHealth/projects/Documents/SAHRC\%20AYADevelopment\%2oLateAdolescentYoungAdulthood.pdf

Walcher, D., Blazek P. and Leube M. (2016). Gender Differences in Online Mass Customization: An Empirical Consumer Study Which Considers Gift-Giving. International Journal of Industrial Engineering and Management (IJIEM), 7(4), 153158. 